\title{
ELECTRON MICROSCOPIC STUDIES OF SOME \\ LUNAR MINERALS
}

\author{
P. E. CHAMPNESS \\ Dept. of Geology, University of Manchester, England \\ and \\ G. W. LORIMER \\ Dept. of Metallurgy, University of Manchester, England
}

\begin{abstract}
Ion-thinned samples of rock 12052 have been examined in the electron microscope at $100 \mathrm{kV}$. This rock contains numerous phenocrysts of pyroxene, $\mathrm{Ca}_{1-\mathrm{P}}$ $(\mathrm{Mg}, \mathrm{Fe})_{1+\mathrm{P}} \mathrm{Si}_{2} \mathrm{O}_{6}$, and a few rounded olivine crystals $(\mathrm{Mg}, \mathrm{Fe})_{2} \mathrm{SiO}_{4}$ set in a finergrained groundmass of pyroxene, plagioclase $(\mathrm{Na}, \mathrm{Ca})(\mathrm{Al}, \mathrm{Si})_{4} \mathrm{O}_{8}$, ilmenite, $\mathrm{FeTiO}_{3}$ and other minor minerals (Champness et al., 1971). The cores of the pyroxene phenocrysts consist of a calcium-poor pyroxene, pigeonite, with an epitaxially grown rim of a calcium-rich pyroxene, augite. Both the pigeonite and augite are zoned, and indication of non-equilibrium crystallisation (Bence et al., 1970).

The outer parts of the pigeonite cores of the phenocrysts show very finescale composition modulations on (001) (major) and (100) (minor) (Figure 1). This texture is interpreted as exsolution by a spinodal mechanism (Cahn, 1968).

The augite rim of the phenocryst exhibits a coarse exsolution of pigeonite on (001) on which is superimposed fine-scale composition modulations on (001) and (100) (Figure 2).
\end{abstract}

The two-stage exsolution process indicates that the cooling rate of the pyroxene increased suddenly, possibly when the magma was extruded on the Moon's surface.

Antiphase domains produced during the polymorphic transition from space group $\mathrm{C} 2 / \mathrm{c}$ to $\mathrm{P} 2{ }_{1} / \mathrm{c}$ have been found in all primary and precipitated pigeonites (Figure 3 ). This confirms Morimoto and Tokonami's (1969) suggestion that all clino-pyroxenes have the $\mathrm{C} 2 / \mathrm{c}$ space group at high temperatures.

Cristobalite, a high-temperature polymorph of silica, occurs as very small grains in the groundmass. It contains numerous microtwins on $\{100\}$ planes produced during the $\beta \rightarrow \alpha$ polymorphic transition which occurs at $268^{\circ} \mathrm{C}$ (Figure 4a). Diffraction patterns show extensive diffuse streaks in various directions (Figure 4 b) which corre spond to intersections of planes in reciprocal space with the Ewald Sphere. These diffuse planes originate from the cooperative thermal vibration of Si-O chains parallel to $\{100\}$ and $\{111\}$.

(More detailed accounts of the results reported here can be found in Proceedings of the 25th Anniversary Meeting EMAG, Inst. of Physics, 324-327 (1971) Contr. Mineral. and Petrol. 33, 171-183 (1971) and in the Proceedings of the 5th International Materials Symposium, Berkeley, California (1972).) 


\section{References}

Bence, A. E., Papike, J. J., and Prewitt, C. T.: 1970, Earth Planetary Sci. Letters 8, 393.

Cahn, J. W.: 1968, Trans. AIME 242, 166.

Champness, P. E., Dunham, A. C., Gibb, F. G. F., Giles, H. N., MacKenzie, W. S., Stumpfl, E. F., and Zussman, J.: 1971, Proc. Second Lunar Sci. Conf. 1, 449.

Morimoto, N. and Tokonami, M.: 1969, Amer. Mineral. 54, 725.

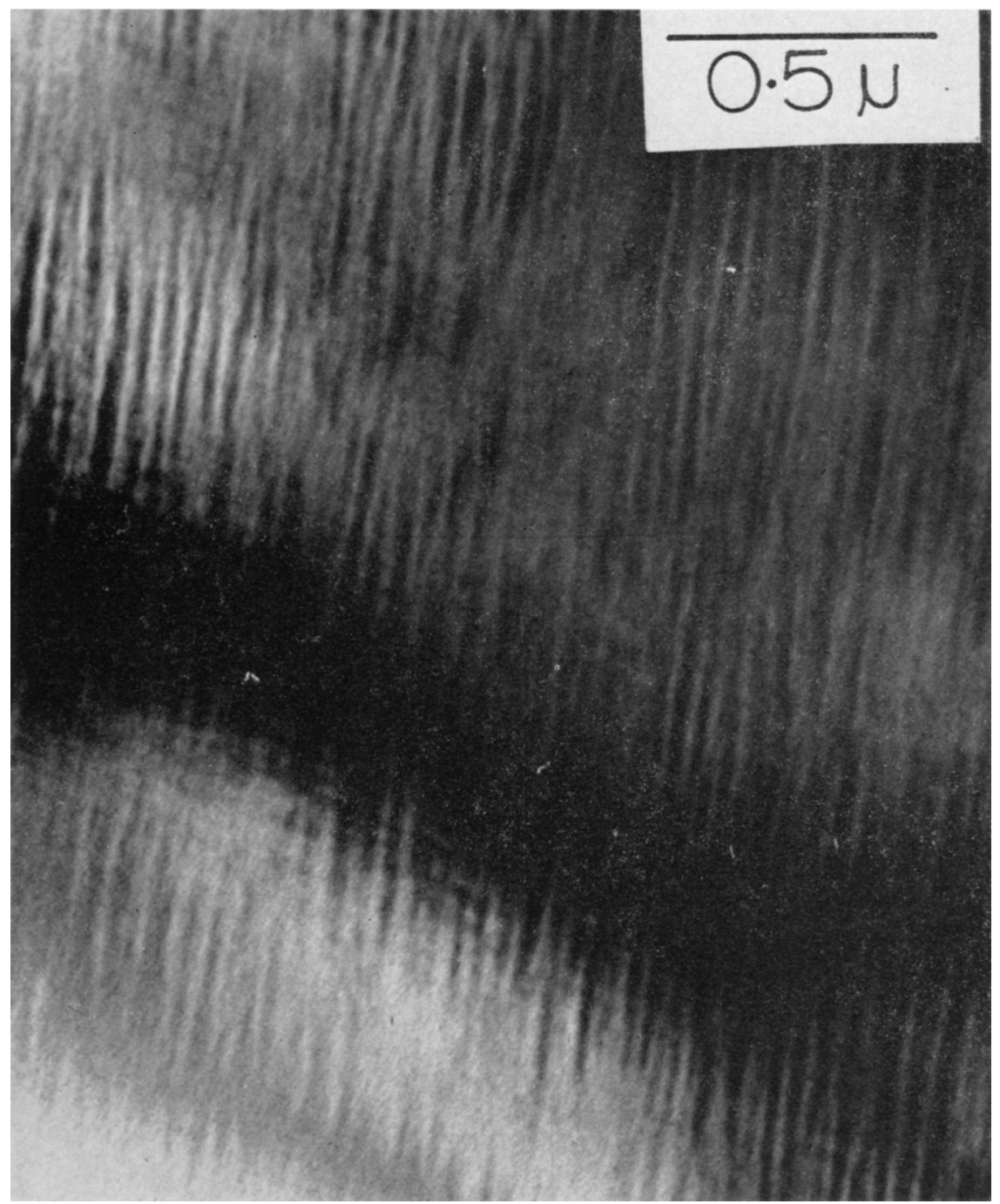

Fig. 1. Electron micrograph of a pigeonite grain in the groundness showing simultaneous composition modulations on (001) (running approximately N-S) and (100). 


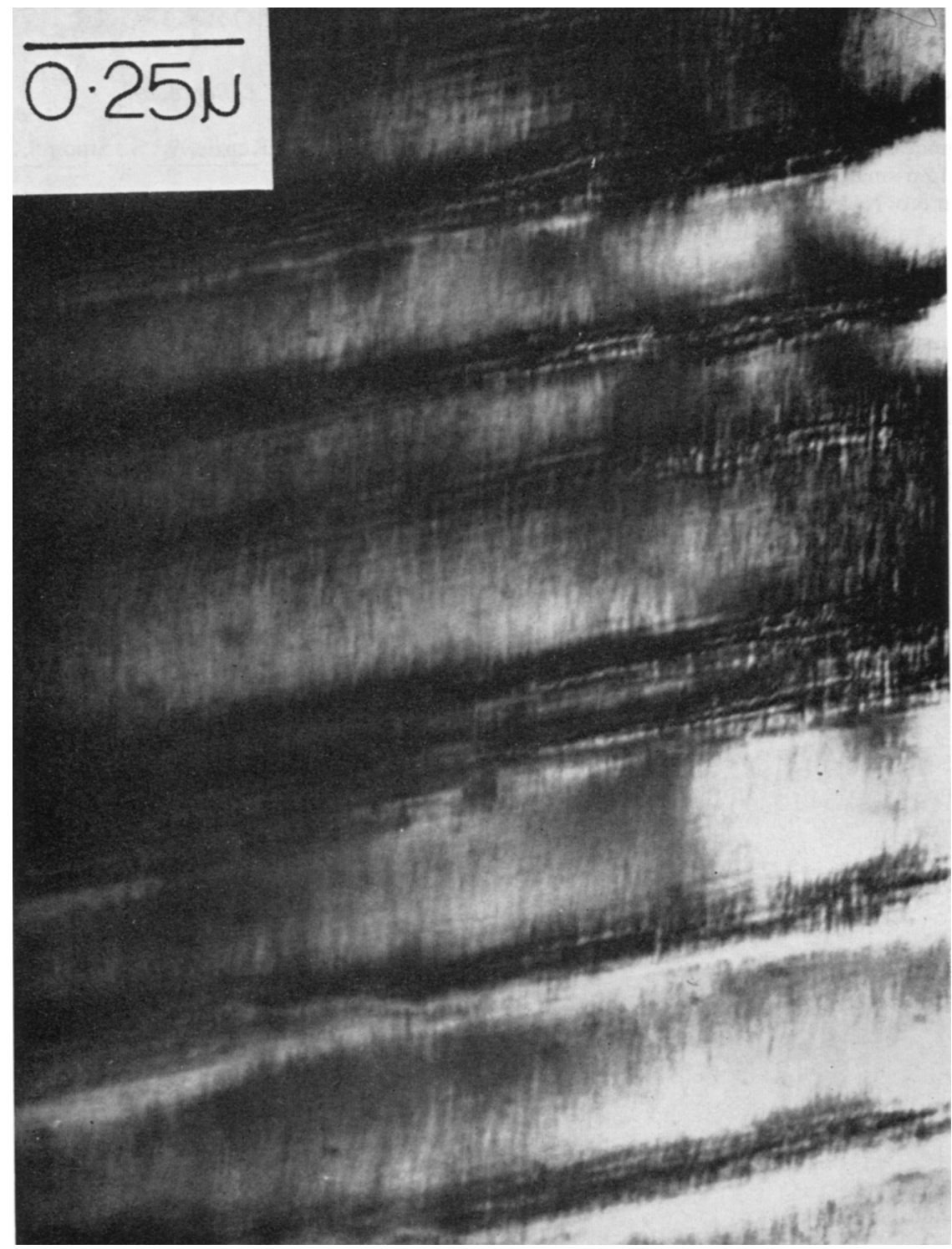

Fig. 2. Electron micrograph of the augite rim of a phenocryst pyroxene showing coarse exsolution of pigeonite on (001) and superimposed fine-scale composition modulations on (001) and (100). 


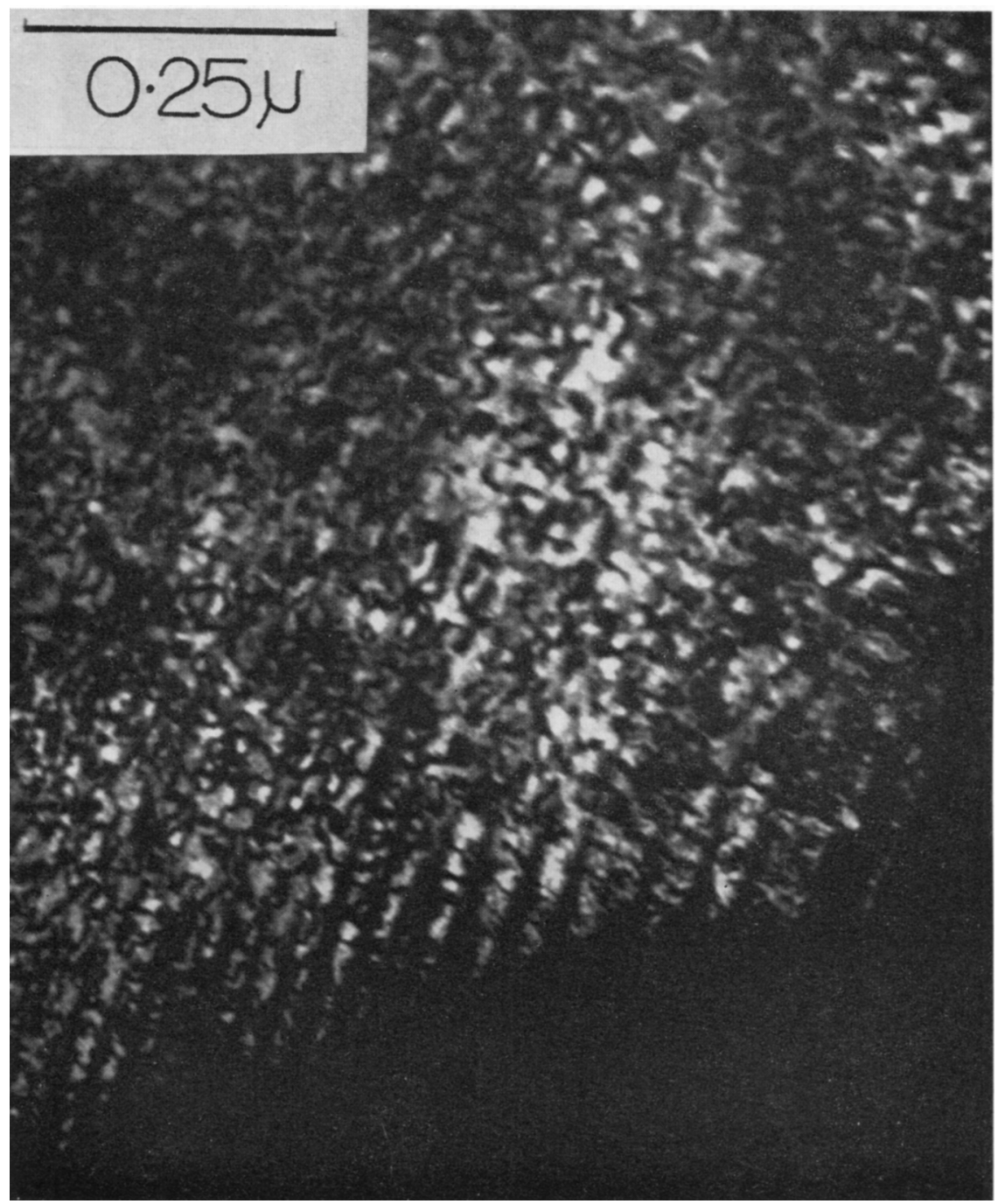

Fig. 3. The outer of the pigeonite core of a phenocryst pyroxene which has unmixed augite. The pigeonite shows antiphase domain boundaries. 

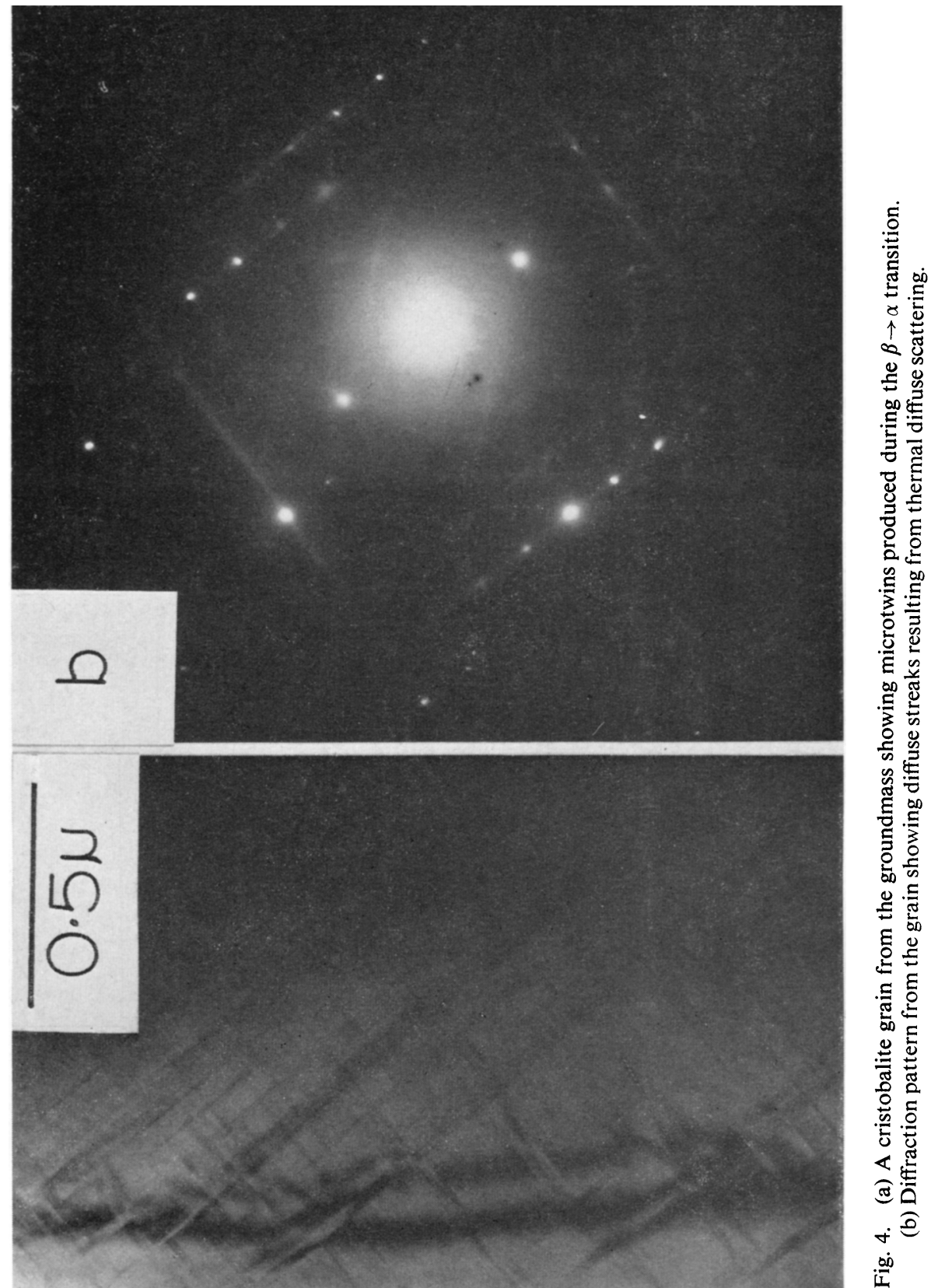

$\nabla$

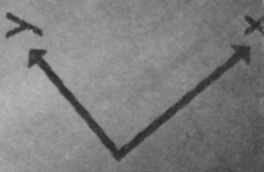

